\title{
Impact of Healthcare Management and Control on Service Delivery, a Case of Oklahoma Healthcare Facilities
}

\author{
Bani Ahmad Amer \\ Kramer School of Nursing, Oklahoma City University, Oklahoma, USA \\ Email: ambaniahmad@my.okcu.edu
}

How to cite this paper: Amer, B.A. (2021) Impact of Healthcare Management and Control on Service Delivery, a Case of Oklahoma Healthcare Facilities. Open Journal of Nursing, 11, 435-441.

https://doi.org/10.4236/ojn.2021.116037

Received: April 27, 2021

Accepted: June 8, 2021

Published: June 11, 2021

Copyright $\odot 2021$ by author(s) and Scientific Research Publishing Inc. This work is licensed under the Creative Commons Attribution International License (CC BY 4.0).

http://creativecommons.org/licenses/by/4.0/

(c) (i) Open Access

\begin{abstract}
Background: Healthcare management and control have been essential to any economy and a concern for most nations. Health care being in the service industry gives another challenge as they are inseparable from the service providers. As a result, a significant focus should be made on the management and control of healthcare. A study is necessary to establish how such practices influence service delivery within the healthcare industry. Objective: To show the influence of health care management and control on the service delivery in the health sector and to establish the impact of health care management system on the delivery of health services, find out the extent to which health leadership has influenced service delivery in the health industry and to establish the existence of healthcare control practices in the health industry and their impact on service delivery. Methods: The general information questionnaire, interviews patient's satisfaction scale, and the hospital performance index were investigated by interviewing 42 healthcare workers working in Oklahoma hospitals. The study utilized a combination of data collection instruments, questionnaires, and interviews for primary data collection and a cross-sectional survey for secondary data from healthcare records within the healthcare facilities. The research adopted a descriptive statistics methodology for data analysis. The study tested the validity of data collected and reset test for omitted variables and simple correlation analysis. Results: effective healthcare management yields reasonable patient satisfaction and ignites motivation among healthcare workers. Additionally, quality service delivery is a function of proper healthcare management systems. Although it is impossible to measure effective management through observation, the testimonies and satisfaction levels among the nurses and the patients communicate accurately.
\end{abstract}

\section{Keywords}

Healthcare, Management, Service Delivery, Control, Hospital, Nurses, 
Patients, Physician, Control, Service Delivery, Patients, Leadership

\section{Introduction}

However, some parameters are difficult to measure and conclude that healthcare management is effective. Globally, most hospitals struggle to meet the expectation and demands of patients [1]. Patients prefer where they are getting more quality services after a short period. It is imperative to note that in most Oklahoma healthcare facilities, the concept of strategic managerial skills has been used to influence the positive outcome. There are internal factors that affect healthcare management in hospitals and patient-related factors. All these factors are interrelated such that when one factor dramatically affects the health care system, other factors are involved too. To assess the impact of healthcare management in-depth, the contribution of healthcare managers, healthcare providers, and decision maker's views must be taken into consideration. The place that requires visionary and dynamic leadership is the health care system. This is because any lapse from either the parties may lead to a permanent effect on an individual's life.

It is important to note that there are factors that affect healthcare management that can be improved to ensure there is quality in the services. The patient's socio-demographic factor is a significant concern. Oklahoma has a higher number of foreign nationals visiting the various healthcare providers. Sometimes there is a total communication breakdown to the extent that the nurse and the patient cannot understand each other [2]. The patients sometimes do not the medical instructions. Sometimes the cultures of the patients affect the provision of healthcare. Interestingly, some male patients do not have instructions from female doctors due to cultural issues [3]. Other patients ask the clinical officers to prescribe them sometimes medicine of their choice that does not treat their sickness.

Another factor that influences healthcare management is the competence of the healthcare providers. Having doctors that are well-trained plays a crucial role in the provision of quality healthcare services. They take time to diagnose correctly and monitor the progress to ensure that the response is what was expected from the onset. Another factor is the lack of appropriate referral systems. Hospitals should be flexible and respond according to the patient's demands. For example, patients should be able to access the doctor they want. Every healthcare facility should network with other hospitals that will allow them to also refer patients to other facilities offering specialized treatment [4]. In addition, the financial status of the other studies have also shown that healthcare management is attributed complex to measure because its success lies beyond what can be seen and the patient's testimonies. In other words, a magnificent building with poor doctors' working conditions is immaterial. The doctors and nurses are the primary healthcare workers, and their satisfaction leads to robust output levels. In 
other words, the healthcare system should have the required resources for effective service delivery. The human capital should be adequate and with the desired competencies to ensure medical errors are minimal. Some patients are highly learned, and they expect competent doctors to address their ailment concerns to which sometimes they know about.

Patient cooperation is also a critical factor that influences healthcare management [5]. When the doctor does the requirement, and the patients fail to adhere to the doctor's instructions, the primary objective of that particular treatment will not be met. The desired clinical outcomes typically depend on the nurse and the patient's cooperation levels. If the doctor prohibits the patients from eating a particular food, that should be adhered to because they know the effects of the said medicine. Quality healthcare management is achievable when the cooperation between the doctor and the patient is good.

Finally, the type of illness that the patient is suffering from can affect the quality of healthcare management. Some diseases require full-time supervision of the nurse. For instance, cancer hospitals tend to pose job-related stress to most doctors. When the doctors see young people battling cancer and losing the fight for life, it affects their psychological stability. Additionally, severe illnesses lead to an increase in the number of deaths. When a given health facility in Oklahoma is associated with extinction, there is a flawed healthcare management system.

\section{Methods}

The study uses a questionnaire to collect essential data from 40 Oklahoma healthcare workers in five hospitals. The study covered different categories of healthcare workers that filled the questionnaire. The classes involved were patients, the healthcare providers, and the managers of the healthcare facilities. Two policymakers from the State Policy Makers Council were included in the study. Three of the hospitals were being government-owned, and the other two were private facilities. Filing of the questionnaire and in-depth interview were used to gather the vital information from the 40 doctors. It was noted that after the interview of the $40^{\text {th }}$ doctor, the responses started repeating themselves; hence no need to go beyond the 40 nurses. The questionnaire was responses sent out to those doctors that could not be available for online interview or in-person engagement. The hospitals chosen for this study were randomly selected. The interview focused on the impact of healthcare management and its influence on control and service delivery.

The interviews were recorded electronically to facilitate easy analysis. The content analysis from the interview conducted was utilized to detect code factors that influence healthcare management. The perceptions of the doctors were different from each other. What the male doctors considered as significant factors affecting healthcare administration was contrary to their female counterparts. The responses from the doctors were different as their ages advances. SPSS software was used for quantitative data and descriptive statistics [6]. 
All the participants of this study were adequately informed of the study's objective, and voluntary participation was encouraged. Ethical issues given weight in this study are a high level of confidentiality and anonymity of the responses from the participants.

\section{Results}

The response of the doctors (physicians) on the factors that are influencing healthcare management into three significant categories is tabulated in various tables. Each category is further into three or four themes, as shown in Table 1 below. The factors that affect healthcare management emanates majorly from the patients perspective. These responses are needed on a scale of 1 to 10 from the following themes in this category. The results are based on the patient cooperation and severity of the illness.

Physician factors are those that influence the quality of the service delivery specific to physicians and nurses. The physician factors include job motivation and satisfaction. Other factors like the doctor's competency were given priority in the interview. The responses were measured on a scale of between 1 to 10 . Finally, the last factor is the environmental factor. The doctors' views in this area were on the healthcare system, partnerships, and availability of resources. The ages of the nurses were considered and their gender. The table below shows the basic statistics.

Table 1. Basic statistics.

\begin{tabular}{|c|c|c|c|c|}
\hline & GENDER & $\begin{array}{l}\text { Patient Factors in a } \\
\text { Scale of } 1 \text { to } 10\end{array}$ & $\begin{array}{c}\text { Environmental Factors Influencing } \\
\text { Healthcare Management }\end{array}$ & $\begin{array}{c}\text { Physician Factors on } \\
\text { a Scale of } 1 \text { to } 10\end{array}$ \\
\hline Valid & 42 & 42 & 42 & 42 \\
\hline Missing & 0 & 0 & 0 & 0 \\
\hline Mean & 1.5000 & 7.0000 & 6.5714 & 6.8810 \\
\hline Std. Error of Mean & 0.07809 & 0.19872 & 0.24844 & 0.16058 \\
\hline Median & 1.5000 & 7.0000 & 7.0000 & 7.0000 \\
\hline Mode & $1.00^{\mathrm{a}}$ & 7.00 & 7.00 & 7.00 \\
\hline Std. Deviation & 0.50606 & 1.28784 & 1.61007 & 1.04069 \\
\hline Variance & 0.256 & 1.659 & 2.592 & 1.083 \\
\hline Skewness & 0.000 & -0.144 & -0.209 & -0.024 \\
\hline Std. Error of Skewness & 0.365 & 0.365 & 0.365 & 0.365 \\
\hline Kurtosis & -2.103 & -0.564 & -0.673 & -0.520 \\
\hline Std. Error of Kurtosis & 0.717 & 0.717 & 0.717 & 0.717 \\
\hline Range & 1.00 & 5.00 & 6.00 & 4.00 \\
\hline Minimum & 1.00 & 4.00 & 3.00 & 5.00 \\
\hline Maximum & 2.00 & 9.00 & 9.00 & 9.00 \\
\hline Sum & 63.00 & 294.00 & 276.00 & 289.00 \\
\hline
\end{tabular}


The above table shows descriptive statistics from a sample size of 42 doctors in Oklahoma. Three variables were under investigation. The first is the patient factors and how they influence healthcare management and improve service delivery. The level of influences was measured on a scale of 1 to 10 . The mean response is 7 , and the median responses were at 7 . The number of physicians who felt that patient factors contribute to healthcare management ranged from 5 to 9 . This means that 5 is the influence level of the element. In other words, they don't believe that it contributes much to the patient's factors. On the other hand, nine denotes that patients' factors contribute to management challenges and success.

Table 2 shows the relationship between the various variable that was the understudy. The statistical data was validated, and the correlation was established to determine the correlation coefficient. The valid data used was 42 . This shows the number of physicians that were interviewed. The two variables that were investigated include patient factors and the environmental factors influencing healthcare management. The coefficient of correlation is 0.45 . It is essential the gender correlation was established.

\section{Discussion}

Healthcare requires sound and visionary leadership to ensure that desired outcomes are achieved, and service delivery is effective. The mean of the responses from the interviews from the three categories is 7 . This shows that $70 \%$ of the physicians agree that patient factors influence healthcare management. The male and female physicians had similar responses. The standard deviation for the reaction in this category is 1.28 . This shows the extent of the spread of the influence. Patients' factors also encompass the socio-demographic variables. The physician and the patient should be able to get along. The level of cooperation should be about $90 \%$.

Table 2. Correlations.

\begin{tabular}{|c|c|c|c|c|}
\hline & & GENDER & $\begin{array}{l}\text { Patient Factors in } \\
\text { a Scale of } 1 \text { to } 10\end{array}$ & $\begin{array}{c}\text { Environmental Factors } \\
\text { Influencing Healthcare } \\
\text { Management }\end{array}$ \\
\hline & Pearson Correlation & 1 & -0.225 & -0.120 \\
\hline \multirow[t]{3}{*}{ GENDER } & Sig. (2-tailed) & & 0.153 & 0.450 \\
\hline & $\mathrm{N}$ & 42 & 42 & 42 \\
\hline & Pearson Correlation & -0.225 & 1 & -0.094 \\
\hline \multirow{2}{*}{$\begin{array}{l}\text { Patient Factors in a Scale } \\
\text { of } 1 \text { to } 10\end{array}$} & Sig. (2-tailed) & 0.153 & & 0.553 \\
\hline & $\mathrm{N}$ & 42 & 42 & 42 \\
\hline \multirow{3}{*}{$\begin{array}{c}\text { Environmental Factors } \\
\text { Influencing Healthcare } \\
\text { Management }\end{array}$} & Pearson Correlation & -0.120 & -0.094 & 1 \\
\hline & Sig. (2-tailed) & 0.450 & 0.553 & \\
\hline & $\mathrm{N}$ & 42 & 42 & 42 \\
\hline
\end{tabular}


The physicians in the hospitals also influence healthcare management. Their character and behavior have a direct impact on healthcare management. From that data, the mean response is $7.70 \%$ of the physicians believe that a competent nurse can deliver high-quality services to patients. They can also demonstrate a high level of commitment and resilience [7]. The physician needs proper motivation and job satisfaction level boosted.

Another factor that has impacted healthcare management is the healthcare system. Hospitals should work in tandem with insurance companies to ensure patients can easily access healthcare services. The doctors and patients should have total trust so that they can work in agreement. The correlation coefficient shows that more males have a different perspective on what affects healthcare management. $45.7 \%$ of the males believe that healthcare management is affected by healthcare systems. Poor remuneration of physicians and lack of job satisfaction affect healthcare management in totality. $33.8 \%$ of the female physicians felt that lack of patients' cooperation negatively impacted the healthcare management.

\section{Limitations and Implications for Further Research}

All the respondents were physicians with little age difference margin. This study cannot be generalized because a variable was not compared to the other; hence, drawing the relationship was impossible. Future research may focus on the qualitative aspect of the study and not the quantitative data that made it difficult to predict specific statistical measurements.

\section{Conclusion}

This investigates the implication of certain factors in influencing healthcare management among physicians. Healthcare management will be effective if good patient cooperation, healthcare systems, and physicians' job satisfaction [8]. The findings are important to policymakers who are critical players in influencing resources to public hospitals for better quality.

\section{Acknowledgements}

The author wishes to thank the physicians who took part in this study.

\section{Conflicts of Interest}

The author declares no conflicts of interest regarding the publication of this paper.

\section{References}

[1] Bigelow, M. (2020) Change Control and Change Management. In: Terrell, W.H., Tom, W. and Lisa, A.G., Eds., Implementing Information Security in Healthcare, HISS Publishing Centre, New York City, 203-214. https://doi.org/10.4324/9781003126294-17

[2] Hsiao, S.-J. and Tseng, H.-T. (2020) The Impact of the Moderating Effect of Psy- 
chological Health Status on Nurse Healthcare Management Information System Usage Intention. Healthcare, 8, 28. https://doi.org/10.3390/healthcare8010028

[3] Brino, K.A.S. (2020) Pediatric Mental Health and the Power of Primary Care. Journal of Pediatric Health Care, 34, e12-e20.

https://doi.org/10.1016/j.pedhc.2019.09.013

[4] Khatoon, A. (2020) A Blockchain-Based Smart Contract System for Healthcare Management. Electronics, 9, 94. https://doi.org/10.3390/electronics9010094

[5] Price, B. (2020) Ethical Challenges in Delivering Person-Centered Care. Primary Health Care, 30, 34-41. https://doi.org/10.7748/phc.2020.e1597

[6] Shakil, K.A., Zareen, F.J., Alam, M. and Jabin, S. (2020) BAMHealthCloud: A Biometric Authentication and Data Management System for Healthcare Data in Cloud. Journal of King Saud University-Computer and Information Sciences, 32, 57-64. https://doi.org/10.1016/j.jksuci.2017.07.001

[7] Alves, O.M.A., Moreira, J.P. and Santos, P.C. (2020) Developing Community Partnerships for Primary Healthcare: An Integrative Review on Management Challenges. International Journal of Healthcare Management, 1-19. https://doi.org/10.1080/20479700.2020.1723882

[8] Singh, I., Kumar, D. and Khatri, S.K. (2019) Improving the Efficiency of E-Healthcare System Based on Cloud. 2019 Amity International Conference on Artificial Intelligence (AICAI), Amity University, Dubai International Academic City, Dubai, 4-6 February 2019, 930-933. https://doi.org/10.1109/AICAI.2019.8701387 